\title{
Role of beta-2 microglobulin in renal dysfunction of Neonates with Birth Asphyxia
}

\author{
Chaudhary GS 1 , Chaudhary $V^{2}$, Dagar $S^{3}$, Singh $A^{4}$ \\ ${ }^{1}$ Dr Ghanshyam Chaudhary, MD (Paediatrics), Associate Professor, Department of Paediatrics, MLB Medical College \\ Jhansi, UP, India, ${ }^{2}$ Dr Vidya Chaudhary, MS (OBG), Associate Professor, Department of Obstetrics and Gynaecolgy, \\ MLB Medical College Jhansi, UP, India, ${ }^{3}$ Dr Sunil Dagar, MD (Paediatrics), Assistant Professor, Department of \\ Paediatrics, Muzaffar Nagar Medical College Muzaffar Nagar, UP, India, ${ }^{4}$ Dr Arvind Singh, Assistant Professor, \\ Department of Community Medicine, Muzaffar Nagar Medical College Muzaffar Nagar, UP, India.
}

Address for correspondence: Dr Ghanshyam Chaudhary,MD (Paediatrics), Associate Professor, Department of Paediatrics, MLB Medical College Jhansi, UP, India. Email: drgschaudhary@,rediffmail.com

\begin{abstract}
Objective: study was conducted to assess role of beta- 2 microglobulin in renal dysfunction of Neonates with Birth Asphyxia. Methods: Study is a Case control studyand a total of 140 babies were selected for study group as cases of birth asphyxia and 70 normal term babies were selected as control group randomly. Urine samples were taken on day 1,3 and day 7 in all the babies and beta 2 microglobulin (B2M) values were estimated in all the babies by ELISA method from urine samples. Results: The mean value of beta 2 microglobulin ( B2M) in neonates with birth asphyxia were 10.53 $\pm 6.03,8.25 \pm 3.56,6.25 \pm 2.72 \mathrm{mg} / \mathrm{L}$ and in neonates of control group were $1.61 \pm 1.01,1.51 \pm 1.04$ and $1.54 \pm 1.03$ $\mathrm{mg} / \mathrm{L}$ on day 1, 3 and 7. The p-value for these two groups was $<0.001$, which is highly significant. Conclusion: beta 2 microglobulin (B2M) is a sensitive indicator for renal dysfunction. It can even detect subclinical renal impairments in neonates with birth asphyxia which are usually missed by standard renal function tests. It can also be used as early marker or screening test for renal impairments.
\end{abstract}

Key words: Beta 2 Microglobulinuria, Renal Impairments, Asphyxiated Neonates

\section{Introduction}

Beta-2 microglobulins (B2M) are present in most of human cells which is a small polypeptide and is present in all body fluids. It is filtered freely by glomeruli and reabsorbed almost completely $(99.9 \%)$ by proximal convoluted tubules in normal neonates. Increased excretion of urinary $\mathrm{B} 2 \mathrm{M}$, indicates renal tubular dysfunction [1- 3]. Glomerular B2M is a very less used metabolite. It can be used in assessing renal function, especially in babies suspected of renal tubular or interstitial disease. B2M can serve as a nonspecific but as sensitive marker of various infectious conditions and neoplastic conditions [4]. There is tubular balance for

Manuscript received:04 $4^{\text {th }}$ Dec 2015

Reviewed: $15^{\text {th }}$ Dec 2015

Author Corrected; 29 ${ }^{\text {th }}$ Dec 2015

Accepted for Publication: 09 $9^{\text {th }}$ Jan 2016
B2M in the human kidney which occurs after 34 weeks gestation and fractional tubular reabsorption of B2M suggested as a useful parameter of renal tubular maturation [5].

There is range of renal damage from oliguria or nonoliguria type of renal failure to renal tubular impairment which can be detected by either traditional tests or by $\mathrm{B} 2 \mathrm{M}[6,7]$.

When we suspect kidney disease, comparing blood and urine levels of $\mathrm{B} 2 \mathrm{M}$ helps to identify whether the kidney is damaged or not. B2M normally is filtered out from blood by the kidney's glomeruli but only partially reabsorbed back into the blood after it reaches the kidney's tubules. The glomeruli can't filter B2M out of 
the blood in glomerular kidney disease; therefore its level rises in the blood and also decreases in the urine.

The tubules can't reabsorb it back into the blood in tubular kidney disease, so its levels rises in urine and blood levels fall. Increased B2M in urine of sick neonates with apparently normal renal parameters indicates subclinical proximal tubular dysfunction especially in birth asphyxia, sepsis and some congenital malformations. The increased levels of urinary beta 2microglobulin in newborn with meconium-stained amniotic fluid denotes the existence of tubular malfunction which is probably due to perinatal distress [8]. 11

The most damaged organ in birth asphyxia of full-term infants is kidney [9]. Birth Asphyxia may be the primary causes of transient renal impairment or it may cause acute renal failure in neonates [10]. There is circulatory adaptive responses to birth asphyxia may cause renal injury as a consequence of decreased blood supply of the kidney. Birth asphyxia causing organ damages are important neonatal problems and it is also challenging for study because it is difficult to measure. The kidney is most sensitive organ to ischemic damage in birth asphyxia. It is the main cause of transient renal impairment or acute renal failure in neonates especially in birth asphyxia.

Persistent elevated level of urinary B2M a sensitive diagnostic tool for subclinical renal tubular dysfunction in neonates but its relevance on long term basis is a matter for future experiments and study [2]. Considering these facts present study is planned to determine the value of Beta $2 \mathrm{M}$ as evidence of renal tubular dysfunction in neonates with birth asphyxia.

\section{Material and Method}

The present study was prospective and hospital based study.It is conducted in Department of Pediatrics Muzaffar Nagar Medical College Muzaffar Nagar U.P. a tertiary care hospital of North India. Ethical clearance was taken from college ethical committee. Study period was over a span of two years from $1^{\text {st }}$ August 07 to $31^{\text {st }}$ July 09 .

Term babies, with gestational age 38-42 weeks by New Ballard scoring system [11], admitted in our NICU with evidence of birth asphyxia, included in study after informed consent.

We selected term babies to rule out any variation in excretion of Beta $2 \mathrm{M}$ due to immaturity of renal function. Neonates were selected by using Apgar score [12] and babies with Apgar Score $<4$ at 5 minutes, were selected for study. Premature babies, babies with evidence of infections, babies with meconium aspiration syndrome, babies with any other sickness and having any congenital renal or other diseases were excluded from study.

A total of 140 babies were selected for study group as cases of birth asphyxia and 70 normal term babies were selected as control group. After taking detailed clinical history, examination and routine investigations, renal function test was done by blood urea and serum creatinine in all the babies.

Urine samples were collected on day 1 in all and on day 3 and day 7 in those having abnormal values in first sample and Beta $2 \mathrm{M}$ values were estimated by ELISA method.

\section{Results}

In the present study 140 cases were taken as study group and 70 normal babies as control group. Following observations were revealed from the study-

Table I: Mean weight of neonates in study and control group

\begin{tabular}{|l|l|l|l|l|}
\hline \multirow{2}{*}{ Group } & No. of & Weight(grams) & \multicolumn{2}{|l|}{ Statistical Significance of difference in mean weight } \\
\cline { 5 - 5 } & Cases & Mean \pm S.D. & Z- test & p value \\
\hline Study Group & 140 & $2780 \pm 350$ & 0.16 & $>0.10$ \\
\hline Control Group & 70 & $2788 \pm 334$ & & \\
\hline
\end{tabular}

From above table it is clear that the mean weight of study group was $2780 \pm 350$ grams and mean weight of control group was $2788 \pm 334$ grams. After applying $Z$ test, $p$ value which was $>0.10$, suggesting statistically not significant. 
Table II: Mean Gestational age of neonates in study and control group

\begin{tabular}{|l|l|l|l|l|}
\hline \multirow{2}{*}{ Group } & No. of Cases & $\begin{array}{l}\text { Gestational Age (weeks) } \\
\text { Mean } \pm \text { S.D. }\end{array}$ & $\begin{array}{l}\text { Statistical Significance of difference in } \\
\text { mean age }\end{array}$ \\
\cline { 3 - 5 } & & Z test & p value \\
\hline Study Group & 140 & $39.53 \pm 0.71$ & 0.07 & $>0.10$ \\
\hline Control Group & 70 & $39.54 \pm 1.14$ & & \\
\hline
\end{tabular}

From above table it is clear that the mean gestational age of study group was $39.53 \pm 0.71$ weeks and mean gestational age of control group was $39.54 \pm 1.14$ weeks. After applying $Z$ test, $p$ value which was $>0.10$, suggesting statistically not significant.

Table III: Beta 2 Microglobulin (mg / L) Value of neonates in study and control group.

\begin{tabular}{|l|l|l|l|l|l|l|}
\hline Day & \multicolumn{2}{|l|}{ Study Group } & \multicolumn{2}{l|}{ Control Group } & \multicolumn{2}{l|}{$\begin{array}{l}\text { Statistical Significance of } \\
\text { difference in mean }\end{array}$} \\
\hline & No. of Cases & $\begin{array}{l}\text { Beta 2 M } \\
(\text { Mean } \pm \text { SD) }\end{array}$ & No. of Cases & $\begin{array}{l}\text { Beta 2 M } \\
(\text { Mean } \pm \text { SD) }\end{array}$ & Z test & p- value \\
\hline D1 & 140 & $10.53 \pm 6.03$ & 70 & $1.61 \pm 1.01$ & 17.03 & $<0.001$ \\
\hline D3 & 131 & $8.25 \pm 3.56$ & 70 & $1.51 \pm 1.04$ & 20.70 & $<0.001$ \\
\hline D7 & 131 & $6.25 \pm 2.72$ & 70 & $1.54 \pm 1.03$ & 18.06 & $<0.001$ \\
\hline
\end{tabular}

As shown in above table the mean value of Beta $2 \mathrm{M}$ in asphyxiated neonates and control group on day 1, 3 and 7 were $10.53 \pm 6.03,8.25 \pm 3.56,6.25 \pm 2.72 \mathrm{mg} /$ Land $1.61 \pm 1.01,1.51 \pm 1.04$ and $1.54 \pm 1.03 \mathrm{mg} / \mathrm{L}$ respectively. P value for these two groups was $<0.001$, which is highly significant.

We also observed from study group babies on day 1, routine renal function tests were abnormal in only 11 (7.85\%) cases and on day 3, in 31 (22.14 \%) cases whereas urinary B 2 M were elevated in $>90 \%$ of cases on day 1 and notably urinary $\mathrm{B} 2 \mathrm{M}$ values were much higher in those showing abnormal renal function tests.

\section{Discussion}

We have selected 140 term asphyxiated newborns as study group and 70 healthy term newborns as control group. We didn't find any statistical significant difference by observing weight of the babies and gestational age of the babies from study and control groups.

We observed that B2M values were increased in study group on $1^{\text {st }}, 3^{\text {rd }}$ and $7^{\text {th }}$ day as compare to control group was statistically significant. Mehta KP et al [2] also observed similar findings. They studied 46 sick neonates (not only asphyxiated neonates as we have done) in study group and 40 normal term neonate in control group.

They have estimated urinary B2M only on day 1 and 3, but we did it on day 7 also in the present study. Tack et al 1987 [13] in their study also reported similar findings.
They took 140 sick neonates (not only asphyxiated neonates) in study group and 35 normal term babies in control group. They estimated urinary B2M only on day 1 and day 3 only but not on day 7 .

We considered many possibilities for an elevated urinary $\mathrm{B} 2 \mathrm{M}$ in neonates including immaturity of renal function, increased generation or decreased reabsorption of $\mathrm{B} 2 \mathrm{M}$ by the tubules due to tubular damage. Aperia A. et al [14] also done a study B2M, an indicator of renal tubular maturation and dysfunction in newborns and they found that absorptive capacity of tubules for B2M was well developed in neonates more than 35 weeks of gestational age.

We included only full tem neonates with mean gestational age of $>38$ weeks, ruled out immaturity of renal system as a cause of increased urinary B2M. 
Other causes of increased B2M in urine could be high blood levels of B2M in neonates with birth asphyxia. As we are aware with the fact that there is very high tubular maximum for $\mathrm{B} 2 \mathrm{M}$, to take over this $\mathrm{T}$ max serum B2M value need to be increased by many folds usually hundred times. Due to this reason increased serum B2M as cause of increased urinary B2M is least possibility.

So by this we concluded that most likely explanation for the observed increased urinary B2M concentration in neonates of birth asphyxia is that these neonates may have pathological lesions in their proximal convoluted tubules that decrease renal tubular reabsorption of B2M. The site for reabsorption of B2M proximal convoluted tubules especially susceptible to injury in asphyxia.

Mehta K P et al [2] in his study found that above $90 \%$ of sick neonates had increased urinary B2M. They also observed that only $17 \%$ of these had abnormal renal function by routine tests. This denotes that B2M can detect subclinical renal impairments those are not detected by routine renal function tests.

What is the importance of detection of subclinical cases of renal impairment is further matter of research. We observed that $>90 \%$ of neonates with birth asphyxia were showing high urinary B2M on day 1 but by standard renal function test only $8 \%$ babies showing abnormalities on day 1 and in $22 \%$ babies showing abnormalities on day 3.It indicates that urinary B2M can be used as early marker of renal impairment in neonates with birth asphyxia.

This is highly sensitive as well as not very expensive and non invasive method to detect renal impairments in asphyxiated neonates. This test can be used as screening test for impending renal failure in neonates with birth asphyxia. The major drawback of this test is lack of specificity may be limiting factor.

\section{Conclusion}

We have concluded that $\mathrm{B} 2 \mathrm{M}$ is a sensitive indicator for renal Impairments. It can detect subclinical renal injuries those may be missed by standard renal function tests. Measurement of $\mathrm{B} 2 \mathrm{M}$ provides a potentially sensitive diagnostic test, which makes possible the diagnosis of previously undetected group of patients with subclinical renal impairment. The importance of these subclinical renal impairments in prognosis \& management of renal dysfunction in birth asphyxia are the further matter of research.

\section{References}

1. Algün E, Topal C, Oztürk $\mathrm{M}$, Sekeroğlu MR, Durmuş A. Urinary beta-2 microglobulin in renal dysfunction associated with hypothyroidism. Int J Clin Pract. 2004 Mar;58(3): 240-3.

2. Mehta KP, Ali US, Shankar L, Tirthani D, Ambadekar M. Renal dysfunction detected by beta- 2 microglobulinuria in sick neonates. Indian Pediatr. 1997 Feb;34(2):107-11.

3. Willis F, Summers J, Minutillo C, Hewitt I. Indices of renal tubular function in perinatal asphyxia. Arch Dis Child Fetal Neonatal Ed. 1997 Jul;77(1): F57-60.

4. Bethea M, Forman DT. Beta 2-microglobulin: its significance and clinical usefulness. Ann Clin Lab Sci. 1990 May-Jun;20(3):163-8.

5. Engle WD, Arant BS Jr. Renal handling of beta-2microglobulin in the human neonate. Kidney Int. 1983 Sep;24(3):358-63.

6. Mehta KP. Neonatal renal failure. Indian Pediatr. 1991 Jan;28(1):7-9.

7. Pereira S, Pereira BJ. Renal dysfunction in the critically ill neonate--a tropical perspective. Indian Pediatr. 1991 Jan;28(1):11-8.

8. Chen JY, Lee YL, Liu CB. Urinary beta 2microglobulin and $\mathrm{N}$-acetyl-beta-D-glucosaminidase (NAG) as early markers of renal tubular dysfunction in sick neonates. J Formos Med Assoc. 1991 Feb;90(2):132-7.

9. Jenik AG,Cernadas J M C, Gorenstein A, Ramirez J A,Vain N,Armadans M, and Ferraris J R.A Randomized, Double-Blind, Placebo-Controlled Trial of the Effects of Prophylactic Theophylline on Renal Function in Term Neonates With Perinatal Asphyxia, Pediatrics 2000; 105(4): 45. 
10. Karlowicz MG, Adelman RD. Nonoliguric and oliguric acute renal failure in asphyxiated term neonates. Pediatr Nephrol. 1995 Dec;9(6):718-22.

11. Ballard JL, Khoury JC, Wedig K, Wang L, EilersWalsman BL, Lipp R. New Ballard Score, expanded to include extremely premature infants. J Pediatr. 1991 Sep;119(3):417-23.

12. Stoll BJandKliegman RM.The Newborn Infant In:Beherman RE, Kliegman RM and Jenson HB.
Textbook of pediatrics, 17th edn. Philadelphia, WB Saunders Company, 2004:527.

13. Tack ED, Perlman JM, Robson AM. Renal injury in sick newborn infants: a prospective evaluation using urinary beta 2-microglobulin concentrations. Pediatrics. 1988 Mar;81(3):432-40.

14. Aperia A, Broberger U. Beta-2-microglobulin, an indicator of renal tubular maturation and dysfunction in the newborn. Acta Paediatr Scand. 1979 Sep;68(5):669-76.

\section{How to cite this article?}

Chaudhary GS, Chaudhary V, Dagar S, Singh A.Role of beta-2 microglobulin in renal dysfunction of Neonates with Birth Asphyxia. Pediatr Rev: Int J Pediatr Res 2016;3(1):19-23.doi:10.17511/ijpr.2016.i01.05. 